\title{
Creating Automobile Pamphlet Design Methods: Utilizing both Biometric Testing and Statistical Science
}

\author{
Kaori Koizumi (Corresponding author) \\ Aoyama Gakuin University \\ 5-10-1, Fuchinobe, Chuo-ku, Sagamihara-shi, Kanagawa-ken, 252-5258, Japan \\ Tel: 81-42-759-6423Ｅ-mail: c5612124@aoyama.jp
}

Maiko Muto

Aoyama Gakuin University

5-10-1, Fuchinobe, Chuo-ku, Sagamihara-shi, Kanagawa-ken, 252-5258, Japan

Tel: 81-42-759-6423Ｅ-mail: c5611174@aoyama.jp

\author{
Kakuro Amasaka \\ Aoyama Gakuin University \\ 5-10-1, Fuchinobe, Chuo-ku, Sagamihara-shi, Kanagawa-ken, 252-5258, Japan \\ Tel: 81-42-759-6423Ｅ-mail: kakuro_amasaka@ise.aoyama.ac.jp
}

$\begin{array}{lc}\text { Received: Nov. 16, } 2013 & \text { Accepted: December 8, } 2013 \quad \text { Published: January 1, } 2014 \\ \text { doi:10.5296/jmr.v6i1.4569 } & \text { URL: http://dx.doi.org/10.5296/jmr.v6il.4569 }\end{array}$

\begin{abstract}
In today's manufacturing industry, the product design is considered as the most important element that influences customer purchasing decisions. The auto industry in particular demands that companies build vehicles that meet customers' individual demands and thus lead to high customer satisfaction. This study looks at one tool used to promote vehicles - automobile pamphlets - and seeks to identify the sensory impact that changing pamphlet designs has on customers. Specifically, this involves using statistical science to (1) visualize the implicit design elements required by customers for automobile design by using an eye camera to analyze the line of sight. Next, (2) identify and quantify the compositional elements of automobile pamphlet design images based on the findings to enable creation of
\end{abstract}




\section{Macrothink}

automobile pamphlet designs. Then, (3) analyze the influence of these compositional elements of automobile pamphlet design images on the customer in sensory terms. Based on the results of this analysis, (4) create automobile pamphlet design images that will be appealing to customers, and then (5) confirm the appropriateness of the analysis results by conducting biometric testing for validation using brain activity. The given results of this process were obtained.

Keywords: Automobile, Design approach model, Pamphlet 


\section{Introduction}

If the authors trace the history of the auto industry through the decades, the authors see that in the 1960s Japanese vehicle design tended to focus on improving driving performance and functionality for city driving at relatively low speeds (up to $60 \mathrm{~km} / \mathrm{h}$ ). As the years went on, however, efforts designed to make customers satisfied - namely, customer satisfaction (CS), customer retention (CR), and customer delight (CD) activities - became increasingly critical. Today, auto manufacturers have to build vehicles that not only deliver functional quality, and environmental features (e.g. fuel efficiency and low emissions), they must also build customer value by offering reasonably-priced cars that anticipate customer life stages and lifestyles. For this reason, inspiring individual customers and getting their hearts pounding is now a vital aspect of the vehicle design process (Amasaka, 2007; Jonker et al., 2006).

\section{Background}

A February 2010 survey conducted in Tokyo that asked automobile buyers to name up to three decisive factors in their purchase decision revealed that $25.6 \%$ considered design/color to be critical - making it the sixth most influential feature. Although an automobile's exterior design and body color play a critical role in sending a message to customers, they are still not as important as price or brand name. Many of today's vehicles do not express or effectively promote a clear concept or message with their design and color.

The authors therefore decided to look at the question of identifying users' rapidly changing needs and accurately addressing them by having auto manufacturers' product planning and design departments incorporate them in well-timed design development strategies and then effectively promoting and advertising the results (Asami et al., 2011; Melewar and Smith, 2003; Satake et al., 2004).

Of the countless studies done on automobile manufacturing, most focus on analyzing customer information, collaboration among automaker departments, design and development, or other individual components of the automaking process. Scientifically analyzing customer information to identify preferences or taking a scientific approach to generating exterior designs and body colors have also been extensively studied, but there has been no methodological inquiry on how to best promote these features in the commercial market (Kawano et al., 2004; Muto et al., 2011; Yamaji and Amasaka, 2009).

\section{Purpose of Study and Guideline}

This study looks at (1) scientifically identifying customer preferences in exterior vehicle design, (2) reflecting those preferences in the development of exterior designs, and (3) effectively promoting the result to the commercial market. Figure 1 proposes a method for creating attractive automobile pamphlet designs in a way that sensitively addresses customer preferences. The steps of the research process as well as the actions taken in each step are outlined below (Fujieda et al., 2007; Koizumi et al., 2013; Takebuchi et al., 2012).

STEP \#1 Preliminary survey 
The first step was to conduct an interview-based survey with automakers to find out the current status of vehicle development and learn exactly how they are creating their pamphlets. The data collected during these surveys was then subjected to cluster and text mining analysis to pinpoint and map out (visualize) underlying success factors.

\section{STEP \#2 Customer preference survey}

The next step was to conduct a survey to identify preferences among younger customers. This data was subjected to a cluster and principal component analysis in order to sort customer preferences into categories and identify a specific target for the study.

STEP \#3 Categorizing images

Thirdly, the compositional elements of automobile pamphlet images were identified so that these images could be separated into categories. This process involved identifying background elements and converting each image and compositional element into binary data. The resulting data was subjected to a cluster and principal component analysis, which yielded eight distinct groups of pamphlet images. The results of the principal component analysis were also used to come up with the distinctive features characterizing each group.

STEP \#4 Linking images and customer preferences

In step 4, an eye camera was used to conduct biometric testing to reveal customers' line of sight as they looked at the pamphlet images. Subjects were also given a survey and asked to rate their sensory evaluation of the pamphlet images so that this data could be collected as well. Finally, the data was subjected to a Quantitative Theory Type I analysis in order to pinpoint the correlation between the compositional elements of pamphlet images and customers' sensory responses.

STEP \#5 Creating a model and verifying results

In step 5, the authors used the results obtained in step 4 to create automobile pamphlet images calibrated towards customer preferences and then proposed a strategic business model that would allow auto manufacturers to create pamphlets that meet customers' sensory preferences. The effectiveness of the strategy was confirmed through a survey that asked target customers to offer a sensory evaluation of the images in the resulting pamphlet. As a result, the strategic business model for creating automobile pamphlet designs was complete.

It is expected that by quantifying automobile pamphlet images and measuring their sensory impact on customers (taking a scientific approach to artistic design), this study will enable designs to be objectively evaluated while serving as a shared tool and means of communicating design information among product planning, design, and other related departments.

\section{Model Adaptation Case}

\subsection{Interview-Based Survey}

The authors conducted an interview-based market survey of design professionals at an 
automaker and paint manufacturer. For the automaker, focus group interviews and customer preference surveys were conducted after narrowing down its target customers. The authors also found that in order to help keep track of customer preferences in a ceaselessly changing modern world, the company had set up a department to research trends in fashion, architecture, furniture, household appliances, and more-with the idea of statistically correlating these movements with the cars that are selling well.

The interviews revealed that the design development process is often implicit, whereby artistic ideas or inspiration is used to come up with a design that is then supported and justified after it is created. Furthermore, because automakers do not know why a given car happens to sell well or what elements drive its market success, they cannot apply those elements to the next design. Finally, although sales personnel and dealers are outwardly collecting customer information, the automobile companies are struggling with the fact that designers are not gathering the data that are needed to effectively develop new ideas.

In an effort to come up with automobile pamphlets that fully showcase a vehicle concept, designers make use of collages to repeatedly test different ideas, making decisions based on their personal sensibilities, gut feelings, and professional intuition. The designers have nothing but a subjective sense of what customers actually look at when they see an automobile pamphlet or how those images make them feel. Though there was an opinion in the company to begin studying customer psychology, there was also confusion about how they might go about doing so. When they create automobile pamphlets, designers are first and foremost considering how they can best communicate the kind of person that would drive the vehicle and the situations in which they might drive it. Though designers select photos that they think will evoke certain images of the vehicle in customers' minds and choose colors that tell a clear story, this process is again dictated by the designers' subjective internal compass. In addition, the authors found that the greatest joy of designers was creating a pamphlet that customers found interesting and engaging - one that stimulated conversation and made everyday driving more fun. It was clear that being able to accurately pinpoint customer sensibilities and preferences and make use of them during the design development process was critical.

Our interview-based surveys revealed that designers were using a subjective, implicit process to come up with vehicle and pamphlet designs. It was also clear that they needed a way to quantitatively grasp customers' sensibilities towards automobile pamphlets so that they could use this information as a tool for developing more effective vehicle designs and market promotions.

\subsection{Charting the Factor Driving Automaker Success}

After listing the success factors identified during the interview-based survey, the authors converted this information into binary data by using the key words we extracted as variables. Table 1 shows the results of this process. The data was then subjected to a cluster analysis in order to classify the different success factors. These results are shown in Figure 1.

After using the cluster analysis to sort the factors driving automaker success into six 
categories, we assigned a definition to each group as shown in Figure 1. The cluster analysis applied Ward's method, correlation coefficients, and standardization

Table 1. 0-1 data that Success Factors and Keywords of Automobile Manufacturers
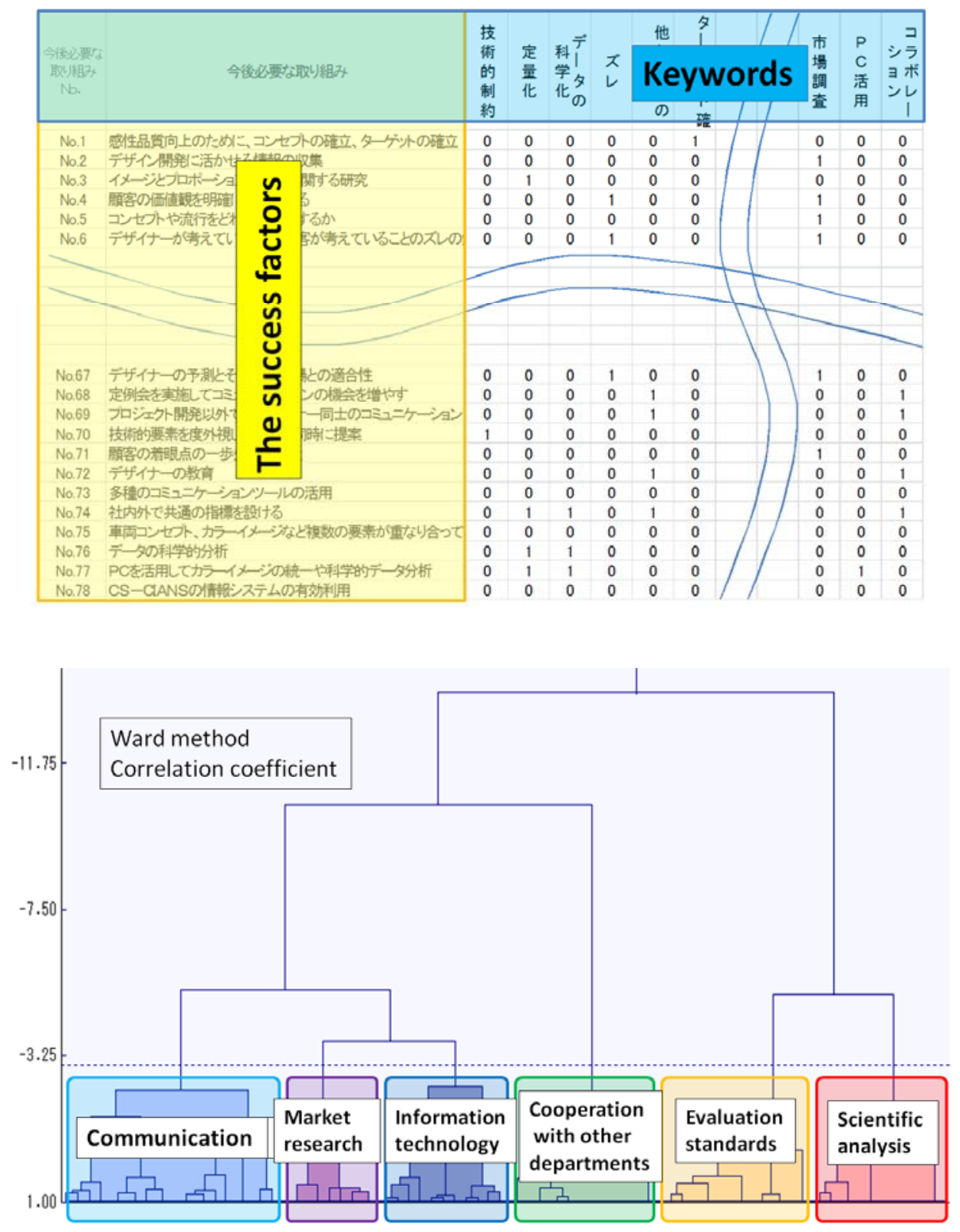

Figure 1. Success Factors of Automobile (Cluster Analysis).

Because the groups of success factors were lacking in specificity after having been sorted only through the cluster analysis, text mining was used to extract key words from each that defined certain focal points for that group. The authors then identified a matrix of partial correlation coefficients and treated these values as the degree of impact each item had on other elements (Table 2). Figure 2 shows the results of the text mining and indicates partial correlation coefficients of 0.5 or higher with arrows. The same analysis was repeated for the other five groups, thus clarifying the degree of impact among elements in each. 
Table 2. Partial Correlation Coefficient Matrix of Communication Elements

\begin{tabular}{|l|l|l|l|l|l|l|l|l|}
\hline \multicolumn{2}{|c|}{ partial correlation coefficients } & & & & & & & \\
\hline & & 1 & 2 & 3 & 4 & 5 & 6 & 7 \\
\hline 1 & $\begin{array}{l}\text { Cooperation with other } \\
\text { departments }\end{array}$ & - & & & & & & \\
\hline 2 & $\begin{array}{l}\text { Obvious of the required } \\
\text { quality }\end{array}$ & -0.30 & - & & & & & \\
\hline 3 & Creation of new design & -0.53 & -0.40 & - & & & & \\
\hline 4 & Communication & 0.67 & 0.49 & 0.68 & - & & & \\
\hline 5 & Share of purpose & -0.36 & -0.11 & -0.59 & & - & & \\
\hline 6 & Resolution of the shift & 0.41 & 0.24 & 0.52 & -0.63 & 0.75 & - & \\
\hline 7 & Unity of consciousness & 0.28 & 0.28 & 0.21 & -0.37 & 0.27 & -0.25 & - \\
\hline 8 & Standardization & -0.16 & -0.39 & -0.18 & 0.30 & 0.04 & -0.14 & 0.71 \\
\hline
\end{tabular}

Communication (Figure 2)

In reviewing the analysis results, the authors focused on the most powerful correlations - those with partial correlation coefficient value of 0.7 or higher. Since one of the success factors was eliminating discrepancies among designers and having them concentrate on shared goals when communicating with one another, this was something that needs to be prioritized moving forward. It is also important that designers at both manufacturers standardize their work and make sure that they are on the same page in terms of conscious knowledge. Finally, new designs need to be generated in a way that prioritizes collaborative effort and shared goals among departments while eliminating discrepancies.

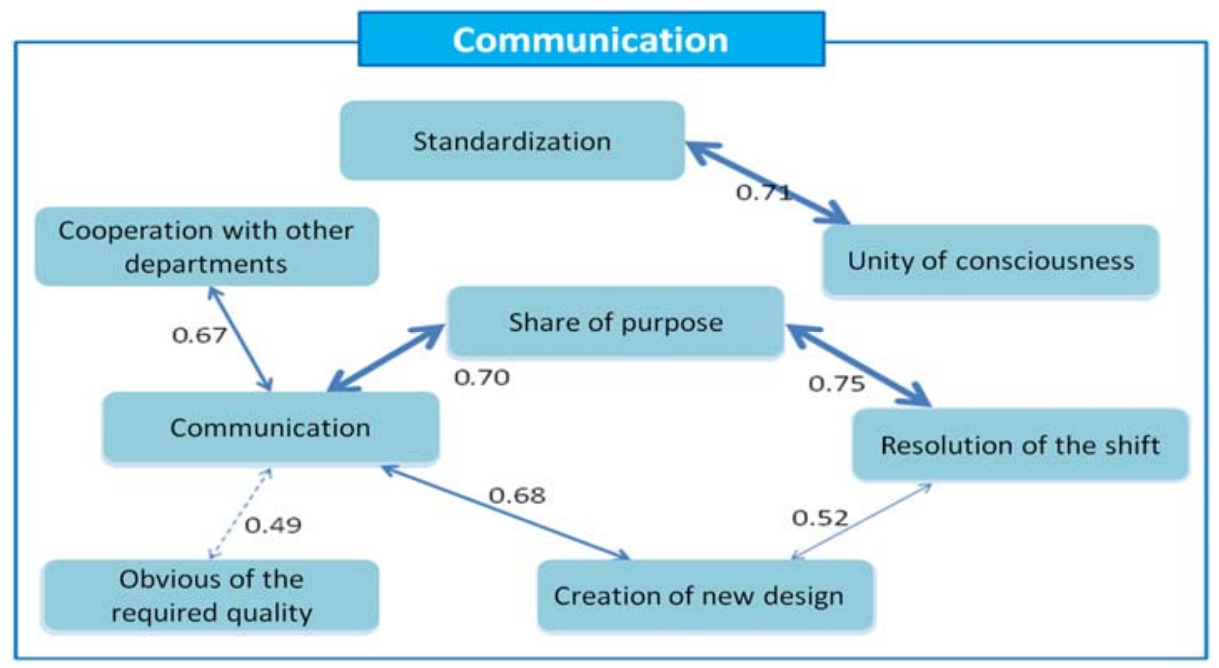

Figure 2. Visualization of Impact that Communication between Elements.

\subsection{Customer Preference Survey}

The survey items were roughly divided into four categories: (1) interested in vehicles, (2) style preferences in terms of vehicle exterior, (3) how to get information on vehicles, and (4) subjective characteristics that described what the person looked for in a vehicle (i.e. "I want a car that's XX"). Questions in categories (1) and (2) identified vehicle preferences among 
younger buyers. Respondents were asked to evaluate the list of subjective characteristics on a seven-point scale. The number of respondents is 52. They are students who have driving license. The questions in (3) identified the methods people use to gather vehicle-related information, while the list of subjective characteristics in (4) was taken from prior research (Ando and Amasaka, 2010) and is shown bottom.

Sophisticated, unique, compact, traditional, rounded, boxy, flashy, cutting edge, practical, chic, sporty, stately, innovative, luxurious, cool, understated, classy, young, classic, stylish and distinctive.

The responses on the preference survey sheets were subjected to a cluster analysis in order to categorize respondents based on their different preferences. The analysis applied sampling classification, standardization, Ward's method, and correlation coefficients in order to divide the test subjects into five preference groups. A principal component analysis was then conducted and meaning assigned to each component. Factor loading and principal component scores were calculated in order to confirm the assigned meanings. Factor loading revealed that principal component \#1 showed strong positive values for subjective characteristics such as "innovative", "flashy", and "distinctive", while negative values were associated with qualities such as "understated" and "classic". Principal component \#2 showed positive values for "compact" and "means of transportation", and negative values in terms of "interest/preference" and "friends/acquaintances". These findings can be interpreted to mean that when it comes to vehicle design, principal component \#1 had an axis indicating whether a person preferred flashier automobiles or those with a more classic look. The axis of principal component \#2 is associated with how people see automobiles, with those that consider them means of transportation and want practicality on one end and those who think of automobiles as an interest or hobby on the other. The cluster and principal component analysis thus revealed the distinctive characteristics of each cluster. These characteristics were expressed by assigning the following labels to each group: (1) practically-oriented, (2) disinterested, (3) self- expressive, (4) practically- and appearance- oriented, and (5) function-oriented.

The authors chose the self-expressive group as the target for the rest of the study due to their strong preferences and desire to express their personal status and image through their vehicle. This group was also the most interested in automobiles. The subjective characteristics that self-expressive types tend to look for were identified as "classy", "luxurious", "sporty", and "stately" using a factor loading scatterplot diagram. The authors also found that this group tends to gather information on vehicles primarily through pamphlets.

\subsection{Identifying Pamphlet Image Elements}

Images were selected for this study by first identifying the characteristics of the numerous pamphlets currently circulating in the marketplace. In order to create automobile pamphlets that effectively appealed to preferences of the self-expressive group, the authors identified the impression that these pamphlets were communicating to group members. The authors took images from several pamphlets currently in the market, extracted the compositional elements of each image, and then categorized them based on their characteristics in order to choose the 


\section{Mll Macrothink}

ones to be used in the study. The selected pamphlets were from three Japanese auto manufacturers and featured 16 sedan models. For each one, the authors selected an image in the pamphlet that clearly expressed the concept behind the vehicle. Figure 3 shows the primary compositional elements: nature (fresh greenery, grassy meadows, fall leaves, cliffs, rocks, mountains, bamboo groves), structures (buildings, homes, facilities, castles), light (sunlight, setting sun, night scenes, artificial lighting), water (rain, snow, fountains, spray, oceans, rivers), sky (blue skies, sunsets, night sky), terrain (cobblestones, roads, asphalt, other surfaces), and miscellaneous elements (indoor scenes, compound backgrounds). All of this information was converted into binary data. A cluster analysis was conducted using the binary data assigned to the compositional elements in order to group the pamphlet images. Each image was sampled (87 types) and the compositional elements of the background images were used as explanatory variables (26 types). As a result, the images were divided into eight groups. The same data was then subjected to a principal component analysis, where eight groupings were identified on a principal component score scatterplot diagram. The following characteristics were identified (cluster \#1).

Cluster\#1: Sky 2 (evening sky) + static

The images in this group show a parked (static) vehicle against a background that is dominated by the sky, which tends to show evening or a sunset.



Figure 3. Grouping of the Image.

\subsection{Modeling and Verification}

\subsubsection{Linking Pamphlet Images and Customer Preferences}

One image from each of the eight groups was brought up on a computer screen individually. Subjects were fitted with an Eye Mark Recorder and asked to look at the images while the device tracked their eye movements. The results revealed that most of the subjects looked at both the shape of the vehicle and the background image (scene, structures, nature, etc.). In 
order to study the focus of their attention more closely, an analysis was done to map out (visualize) their areas of interest. This analysis indicated that subjects put the bulk of their attention on the fender (front of the car), front headlights, and the front grille. We then collected subjective evaluations from the self-expressive target group about the images they saw while wearing the eye camera. This was done by having them fill out a survey indicating how much subjective characteristics applied to them using a seven-point scale. The subjective characteristics used in the survey were the ones that the self-expressive group favored (classy, luxurious, sporty, and stately) and the ones used in the selected pamphlets. Respondents were also given free response questions where they indicate why they gave the evaluations. To further link pamphlet elements with customer sensibilities, the authors extracted compositional elements of vehicle exteriors in addition to the elements found in the background images. Variables related to the vehicle exterior were studied by preparing several patterns using the parts where the extracted customers tend to focus their attention. These elements regarding the vehicle exterior are shown below.

Next, the background elements and vehicle exterior elements were used as variables in a Quantitative Theory Type I analysis. The information was converted into binary data using the seven-point evaluations of the subjective characteristics in the survey as objective variables and the extracted background and vehicle exterior elements as explanatory variables. The standard partial regression coefficient was calculated for each variable to find the degree to which the explanatory variables impacted each objective function. Because subjective characteristics were being used as objective variables and compositional elements in automobile pamphlets as explanatory variables, we are able to identify the impact that compositional elements in the pamphlets had on those subjective characteristics by focusing on the standard partial regression coefficients. Figure 4 and 5 show some of the analysis results when "classy" were used as the objective variable. If we look at the standard partial regression coefficient, we see that the compositional element with the greatest impact on the subjective characteristic "classy" is a night sky. This means that when designing images for automobile pamphlets, using a night sky in the background should enable the pamphlet to communicate a "classy" image to customers.

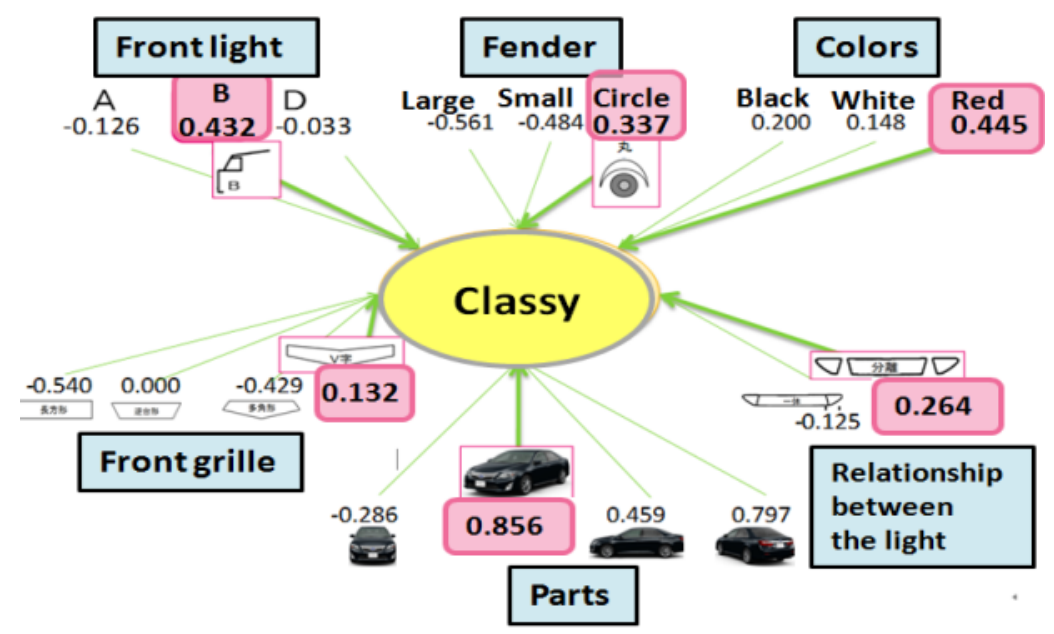

Figure 4. Summary of Standard Partial Regression Coefficients for "Classy" Attribute 
(Variable Regarding the Vehicle Exterior).

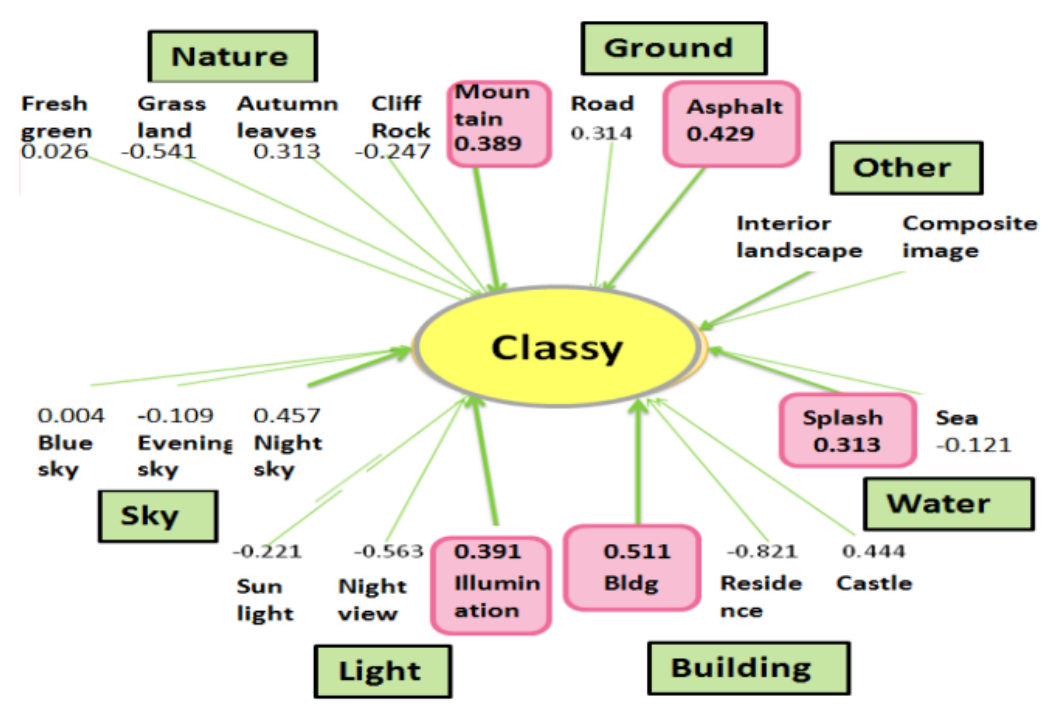

Figure 5. Summary of Standard Partial Regression Coefficients for "Classy" Attribute (Variable Regarding the Background Image)

As Figure 4 and 5 indicate, the elements that have the greatest impact on communicating a "classy" image when it comes to the vehicle exterior are Type A front headlights, a rounded fender, red color, a V-shaped front grille, a slanting nose, and separate fog lights. In terms of background image, the elements that have an influence on communicating a "classy" image are mountains, asphalt, interior scenes, a night sky, night scenes, buildings, and splashing water. The same analysis was conducted for the other attributes (luxurious, sporty, and stately); the results are summarized in Table 3.

Table 3. Summary of Elements Impacting Each-objective Characteristic

\begin{tabular}{|c|c|c|}
\hline Classy & $\begin{array}{c}\text { The elements related to } \\
\text { background image }\end{array}$ & $\begin{array}{c}\text { The elements related to } \\
\text { automobile exterior }\end{array}$ \\
\hline Luxurious & $\begin{array}{c}\text { Type A front headlights, a } \\
\text { rounded fender, red color, a } \\
\text { V-shaped front grile, a } \\
\text { slanting nose, and separate } \\
\text { fog lights }\end{array}$ & $\begin{array}{c}\text { Mountain, bldg, Illumination, } \\
\text { splash, night sky, asphalt, } \\
\text { and interior landscape }\end{array}$ \\
\hline Sporty & $\begin{array}{c}\text { Type B front headlights, a } \\
\text { rounded fender, white and } \\
\text { red color, a V-shaped front } \\
\text { grille, a slanting nose, and } \\
\text { one body fog lights }\end{array}$ & $\begin{array}{c}\text { Fresh green, bldg, night view, } \\
\text { splash, night sky, asphalt and } \\
\text { interior landscape }\end{array}$ \\
\hline Stately & $\begin{array}{c}\text { Type A front headlights, a } \\
\text { large fender, black color, a } \\
\text { polygon front grille, a front } \\
\text { nose, and separate fog lights }\end{array}$ & $\begin{array}{c}\text { Cliff, rock, residence, sunlight, } \\
\text { sea and blue sky }\end{array}$ \\
\hline & $\begin{array}{c}\text { Type A front headlights, a } \\
\text { rounded fender, black color, } \\
\text { anverted trapezoid grille, a } \\
\text { slanting nose, and one body } \\
\text { fog lights. }\end{array}$ & $\begin{array}{c}\text { Fresh green, castle, night } \\
\text { view, night sky and road }\end{array}$ \\
\hline
\end{tabular}

Next, a graphic modeling analysis was conducted in order to identify the interactions between elements that affect each subjective characteristic. If the authors look at the results for the 
subjective attribute "classy" in Figure 6, the authors see that the partial correlations are particularly strong for night scenes, buildings, and red body color. Since night scenes also have a strong partial correlation to Type B headlights, we could combine artificial lighting, buildings, red body color, and Type B headlights to get even closer to creating a classy image.

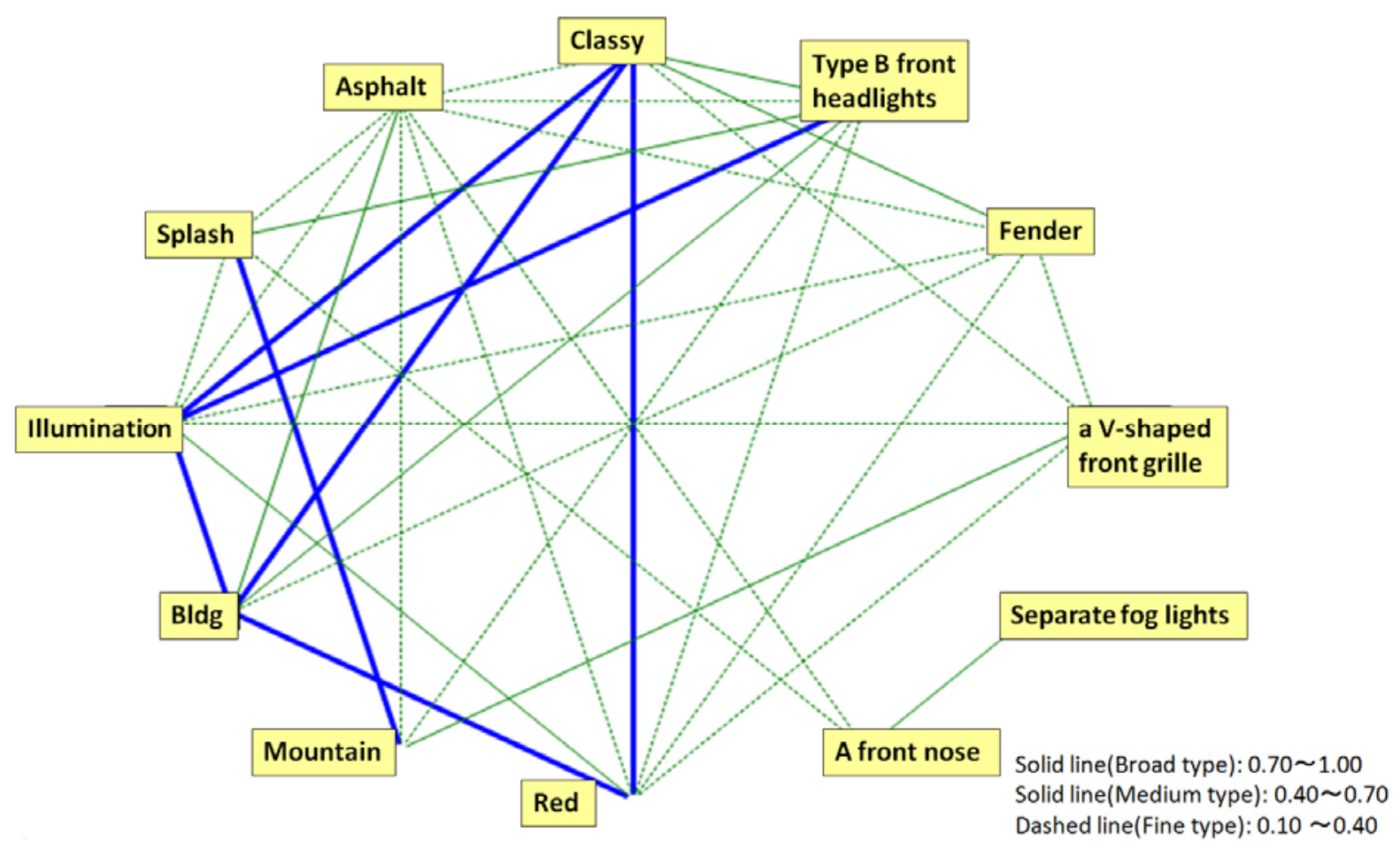

Figure 6. Result of Graphical Modeling (Subjective Characteristic” Classy”)

\subsubsection{Verification}

The above analysis results were used to select an ideal pamphlet image for each subjective characteristic. Based on the graphical modeling results, the authors selected pamphlet images that are used as main compositional elements in pamphlets (Figure 7).

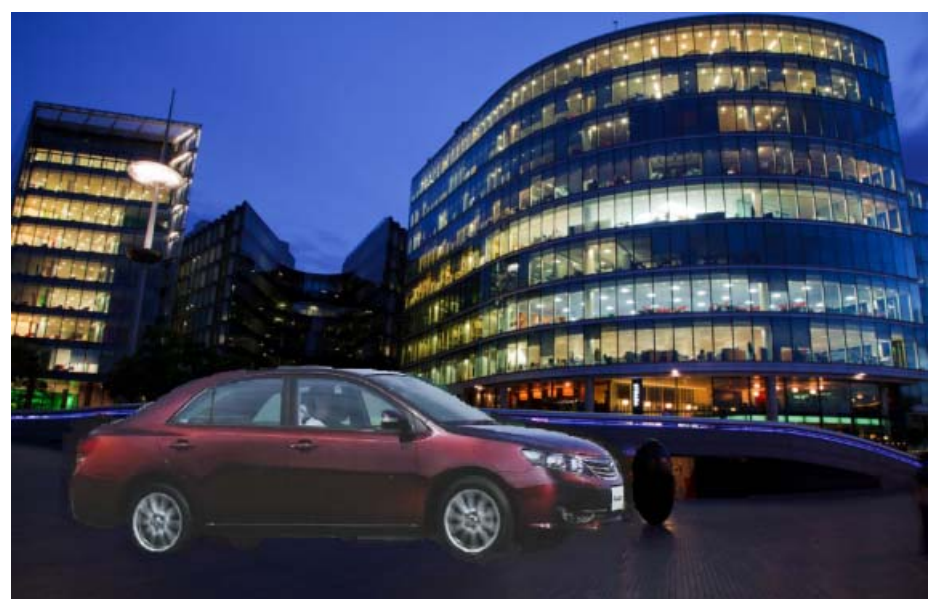

Figure 7. Design Communicating “Classy Image 
In verifying the results of the study, a sensory evaluation questionnaire was used for the four designs that most effectively expressed a "luxurious", "classy", "sporty" and "stately" image to measure subjective impressions. Concretely, respondents were asked to rate each image in terms of how strongly they felt about each of the four subjective characteristics on a seven-point scale. The ten subjects that were given this evaluation questionnaire were different from the ones who were given the earlier survey on subjective characteristics. The results indicated an average "classy" score of 6.6 for the image selected for that attribute, an average "luxurious" score of 6.0 for the luxury image, an average "sporty" evaluation of 6.2 for the sporty image, and an average "stately" score of 6.1 for the stately image-each scoring higher in its particularly subjective category than the other images did on average. In this way, the validity of the analysis results obtained in section 8 was verified.

Preferences were also evaluated using a brain wave measuring device. Human emotional responses can be measured in terms of brain activity, and the cerebrum is the seat of higher mental functions such as perception, movement, thinking, and judgment. Therefore, by measuring the electrical impulses in different areas of the cerebrum gives us clues to predict the relationship between brain activity and human action. Brainwave frequency is categorized into four different ranges: delta waves (up to $4 \mathrm{~Hz}$ ), theta waves (4-8 Hz), alpha waves (8-13 $\mathrm{Hz}$ ) and beta waves (13 Hz and higher). The brains of people who are experiencing emotional calm typically exhibit alpha waves. This fact allows us to use brainwave measurement as an indicator of personal preference - by looking at integrated alpha wave values recorded when a subject views a particular image. The detailed procedure was as follows. Subjects were shown a subjective characteristic along with two different images. One was from existing pamphlets that each subjective characteristic is used to describe the concept, and the second was selected during the study as exemplifying the concept or image of that characteristic. The subjects were given one minute to look at the images while their brain waves were recorded. The proportion of $\alpha$ wave in brochures existing images was about $25 \%$, but the proportion of $\alpha$ wave in the pamphlet images that were selected by the present study was about $60 \%$.

\section{Conclusion}

The research that it was caught about the effective promotion method of the automobile design which gives purchase a great influence quantitatively couldn't be found until now.

So, the authors paid attention to the automobile pamphlet which was one of the means of the promotion of the automobile market, and did research for the purpose of catching the degree of an influence which a change in the pamphlet design gave to the client's sensitivity. Then, it thinks that that is connected with the market expansion of the automobile sales market.

\section{References}

Amasaka, K. (2007). The validity of "TDS-DTM": A strategic methodology of merchandise development of New JIT - Key to the excellence design "LEXUS". International Business \& Economics Research Journal, 6(11), 105-116.

Ando, T. and Amasaka, K. (2010). A Study on Automobile Form Design Support Method “AFD-SM". The Journal of Business \& Economics Research, 8(11), 13-19. 
Asami, H., Owada, H., Murata, Y., \& Amasaka, K. (2011). The A-VEDAM Model for Approaching Vehicle Exterior Design. Journal of Business Case Studies, 7(5), 1-8.

Fujieda, T., Masuda, Y., \& Nakahata, A. (2007). Development of automotive color designing process. Journal of Society of Automotive Engineers of Japan, 61(6), 79-84.

Jonker, J. J., Pielsma, N., \& Potharst, R. (2006). A decision support system for direct mailing decision. Decision Support System, 42, 915-925. http://dx.doi.org/10.1016/j.dss.2005.08.006

Kawano, K., Konjiki, F., \& Ago, Y. (2004). Psychological effects and sexual differences in EEG values during collage making. Journal of International Society of Life Information Science, 22(1), 60-64.

Koizumi, K., Kawahara, S., Kizu, Y., \& Amasaka, K.(2013). A Bicycle Design Model Based on Young Women's Fashion Combined with CAD and Statistics. China-USA Business Review, 12(4), 266-277.

Koizumi, K., Muto, M., \& Amasaka, K.(2013). Methods for Creating Automobile Pamphlet Designs that Will Be Appealing to Customer; Utilizing both Biometoric Testing and Statistical Science. International Congress on Logistics and SCM Systems, Japan.

Melewar, T.C., \& Smith, N. (2003). The internet revolution: Some global marketing implications. Marketing Intelligence\& Planning, 21(6), 363-369. http://dx.doi.org/10.1108/02634500310499220

Muto, M., Miyake, R., \& Amasaka, K. (2011). Constructing an Automobile Body Color Development Approach Model. Journal of Management Science, 2(2), 175-183.

Satake, I., Ando, K., Kuwano, K., Sato, T., Hattori, H., \& Kajiwara, K. (2004). Study on relationship between automotive exterior color and automotive shape category. Journal of the Color Science Association of Japan, 28(2), 102-110.

Takebuchi, S., Nakamura, T., Asami, H., \& Amasaka, K. (2012). The Automobile Exterior Color Design Approach Model. Journal of Japan Industrial Management Association, 62(6), 303-310.

Yamaji, M., \& Amasaka, K. (2009). Intelligence Design Concept Method Utilizing Customer Science. The Open Industrial and Manufacturing Engineering Journal, 2, 21-25. http://dx.doi.org/10.2174/1874152500902010021

\section{Copyright Disclaimer}

Copyright reserved by the author(s).

This article is an open-access article distributed under the terms and conditions of the Creative Commons Attribution license (http://creativecommons.org/licenses/by/3.0/). 